WHEN CHANGE IS NO LONGER ENOUGH: WHAT DO WE MEAN BY 'TRANSFORMATION' IN ORGANIZATIONAL CHANGE WORK?

main author for editorial contact

Dr Paul Tosey

Human Potential Research Group

School of Educational Studies

University of Surrey

Guildford

Surrey GU2 5XH

UK

Tel: $\quad 01483689763$

Fax: $\quad 01483686191$

E-mail: P.Tosey@surrey.ac.uk

Paul Tosey is Head of Learning and Teaching and Director of the Human Potential Research Group at the University of Surrey.

Co-author:

Graham Robinson, Director, Kennedy Robinson Business Development 


\title{
WHEN CHANGE IS NO LONGER ENOUGH: WHAT DO WE MEAN BY 'TRANSFORMATION' IN ORGANIZATIONAL CHANGE WORK?
}

\begin{abstract}
The term 'transformation' is much used in the practice and literature of management and organizations. We are curious as to why there has been little challenge to or questioning of usage of the term.
\end{abstract}

In this paper we identify a number of dimensions on which usage of 'transformation' appears to vary. This results in a tentative classification into a matrix of four types. These are:

a) Change of form or enterprise

b) Corporate Transformation (planned, system-wide change)

c) Learning Organisation initiatives (transforming mind sets and 'paradigms')

d) 'Organizational Transformation' (OT) based on acts of faith and personal commitment, often involving notions of spirituality.

While these clusters overlap they imply a variety of agendas, expectations and modes of working, with widely differing implications for those involved in associated change processes.

The aim of the article is to stimulate debate about the idea of transformation, not to attempt to define what transformation 'is'. Thus we treat this variety of usage as interesting and potentially significant, not as a problem or as an inadequacy of terminology that has to be resolved.

\section{Keywords}

Transformation, Organizational Transformation, change, change management, transformative learning, spirituality. 


\section{On 'Transformation’}

Webster's Dictionary defines transformation as `A change in the shape, structure and nature of something'. Current usage suggests that the term now has a wide range of connotations within the field of organization theory and practice. Many organizations are described as, or publicise themselves as, 'transformed'. For example:

'An example of a transformed organization is IBM, which has undergone two significant transformations in the last 40 years. The first was when they changed their service focus from mechanical devices such as typewriters and keypunches to computers. The second transformational change was a culture change when Louis Gerstner Jr. became their leader.' Achieving a Highly Effective Organization by Glen D. Hoffherr and Robert P. Reid http://www.qualitydigest.com/aug95/achieve.html

Frequently, people cite transformation as an achievement ('he transformed the organization from a functional team to a business team structure') and copious consultancy and business service organisations claim to be delivering 'transformation' ('XYZ deliver organizational transformation with some of the foremost expert practitioners and methods to align process, organization and technology to fit new strategies for navigating through the transition').

In such usage, ‘transformation' functions variously as a description of something that has happened, as a claim that something has been achieved, and as a promise or an aspiration about what might be achieved.

Transformation is often posed as an imperative, a necessity for survival and the only alternative to corporate oblivion. Blumenthal and Haspeslagh, writing about 'corporate transformation', say that 'The first step, of course, is to recognise that the firm is or will become uncompetitive.' (1994 
p.102). Gordon (1994) suggests that 'While once high-performing organizations, such as Delta Airlines, Digital Equipment Corporation, and Kodak have faltered, some of their counterparts such as Xerox and General Electric, have already begun the transformation required to compete in the 21st century'.

The literature of organizational change uses the concept of transformation freely. Pedler, Boydell and Burgoyne (1989 p.2) define the Learning Company as `an organisation which facilitates the learning of all its members and continually transforms itself.' Ackerman (1986) sees transformation as the highest form of organizational change, following on from development and transition. In contrast Barrett (1998) describes transformation as a phase between change and evolution (the latter, according to Barrett, being the pinnacle to which change managers should aspire).

Reference to 'corporate transformation' is common (for example Kilmann et al 1988; Blumenthal and Haspeslagh, 1994). There are also related concepts - but outside the scope of this article such as ‘transformational leadership' (Burns, 1978; Bass and Avolio, 1994); and ‘transformational learning' (Kofman and Senge 1993), a variant on 'transformative learning' (Mezirow 1991) in the field of adult learning and professional development.

In short, transformation is probably one of the most commonly used terms in relation to organizational change work. The material so far illustrates that 'transformation' does not necessarily mean anything at all, quite apart from the question of the extent to which practice matches rhetoric. Rather than being understood necessarily as a descriptor of some identifiable phenomenon, the term also needs to be seen as a linguistic or discursive device, representing a claim or an aspiration, used in service of imperatives, and attached to types of theories and practice.

Looking at the broad picture, we might see this as effectively a declaration that 'change' is no 
longer adequate, either as a description or as an aspiration. Change is everywhere, and has been for several years. Transformation, it seems to be implied, is on a higher plane and therefore more worthy of serious consideration. As such it may be a means of re-engaging managers' and employers' attention, or a means of marking out current thinking and practice as novel and different. Perhaps the connotations of change in an organizational context have become so negative that now some alternative is sought. One of our colleagues, for example, commented recently that whereas `change' seems a ‘cold' word, 'transformation' appears `warm'. If so, such connotations may be very transient. Consultancies claiming to deliver 'transformation' are frequently those offering systems and business process solutions - hardly the 'warmest' variety of change programme.

Whatever the reasons, we suggest it may be more useful to ask what 'transformation' denotes or implies, than try to examine what transformation 'is', although it is not our intention to develop any formal linguistic analysis along these lines. One significant concern here is that, if the territory of transformation is so amorphous, how are practitioners engaging effectively with issues of intent, ethics, evaluation and criticality?

\section{How transformation is defined: issues and variations}

Next we identify and comment on three sets of issues pertinent to how definitions or understandings of transformation seem to vary. In the following section we synthesise these into a matrix of typical usage.

\section{Criteria for transformation: from behaviour to paradigm}

Transformation is often implied or stated to achieve or represent a qualitatively different state. If so, how much agreement and variation exists about how we can tell that transformation has been achieved? What are proposed as criteria for transformation? What counts as transformation, and 
how is it measured?

Blumenthal and Haspeslagh's analysis of corporate transformation is `based on a review of dozens of transformation cases and interviews with senior managers, academics, and consultants' (1994 p.101). They do not specify the nature of these cases or informants, nor do they refer to published sources of this material. Their conclusion is that 'While the goal of all transformations is to improve performance, many efforts to improve performance are not transformational. We propose that to qualify as a corporate transformation, a majority of individuals in an organization must change their behaviour. (ibid p.101)'. They distinguish sharply between 'transformation and other changes, such as restructuring, in which a firm is reshaped... without necessarily affecting the nature of managers' and employees' work'. (p.101-2). Blumenthal and Haspeslagh do not offer any guidance as to how this sharp distinction is made in practice.

Another common but different emphasis, typical with authors associated with the theme of the learning organization such as Pedler et al (1991) and Senge (1990), is on a shift in fundamental assumptions or ways of seeing. Pedler (1994 p.147) says, in relation to double-loop learning (Argyris 1987), which he acknowledges as being linked to the idea of transformation: 'Core to the argument is whether these changes constitute a fundamental change in operating assumptions or whether the learning took place within the current business perspective.' The suggestion is that the transformed corporation not only demonstrates success where previously there was failure but also has a membership that adopts different beliefs and shared values concerning that organization's direction and future performance. Senge uses the term 'mental models', which he defines as `deeply ingrained assumptions, generalizations, or even pictures or images that influence how we understand the world and how we take action' (1990 p.8).

Roger Harrison has a similar emphasis; 'It is a truism that many if not most organizations are engaged in transformation, by which I mean a change in our fundamental ways of perceiving, understanding, and valuing the world about us (sometimes called a paradigm shift).' (Harrison, 
1995 p. 397). Dehler and Welsh speak of Organizational Transformation transcending `the rationality associated with the traditions of scientific management to invoke a new management paradigm...' (1994 p. 18). Similarly, Nutt and Backoff (1997) include in their analysis the statement that 'to transform an organization, its leaders must create and implement a paradigm shift' (1997 p.239). French and Bell are authors of a classic book titled 'Organization Development' (for example, 1978 second edition). French, Bell and Zawacki (1994) authored the fourth edition of this volume, the title of which had then become 'Organization Development and Transformation'. Addressing this change in title, they comment as follows:

'Organization transformation is the application of behavioral science theory and practice to effect large-scale, paradigm-shifting organizational change. An organizational transformation usually results in totally new paradigms or models for organizing and performing work' (French et al, 1994 p.1).

‘Paradigm', like `transformation' seems to be an over-used term. `New paradigms' in management are hailed by the week. Thomas Kuhn's book (1970, originally published in 1962) is the main source of contemporary usage of the term. His interest was in tracing changes in scientific thought and practice, especially changes at a fundamental level. An example is the contrast between the Newtonian view of a mechanical universe and Einsteinian relativity (which is debated in Kuhn's book). Kuhn also used the term in another, different sense to indicate particular examples (the literal meaning of 'paradigm') that point the way to tackling scientific puzzles. In contemporary usage, 'paradigm' seems to refer in a highly localised way to a specific organization's beliefs and assumptions, perhaps even to fleeting changes of language.

As an example from an account of a specific change process, Robinson and Hurley (1996) review of their work with the States of Guernsey (in the British Isles). They describe how, in a conference presentation, their usage of the term 'transformational learning' to characterise changes in the client organisation was seen as contentious `...particularly as much of the content and process of 
the programme drew on the tried and tested rather than on the radical, the new and the innovative'.

They felt the label 'transformation' was justified: 'However, we stand by the use of that phrase, since the management climate is now totally different from that which existed when the process began. From a climate characterized by "turfism", defensive organizational relationships, "not invented here" resistance to change, etc., the situation has changed to one in which crossorganizational policy development, problem-solving and futures planning groups are commonplace and where barriers between organizations, functions and grade levels... have been lowered significantly.' (1996 p.19)

For Robinson and Hurley the key criterion was the qualitative difference from what existed before. Their critic, on the other hand, proposed an additional criterion of innovative or radical features leading to a fundamental shift in the perspective of organizational members.

In summary, sources typically imply that transformation involves a definite qualitative rather than incremental difference. The type of qualitative difference cited may be, for example, a widespread change in behaviour. There is a frequent association between transformation and the idea of introducing or producing a 'new paradigm'. What constitutes a new paradigm seems problematic, remaining open to interpretation and likely to vary according to agenda, perspective, point in time, and so on.

\section{Transformation is... bigger, wider, deeper}

As well as being defined with reference to its effects, transformation is also defined relatively, usually in comparison with other types of change or change programme. Organizational Transformation (OT) is contrasted with Organization Development (OD) in various ways, and typically such comparison appears metaphorical rather than literal, with OT said to be (for 
example) wider, deeper, bigger or longer-term; Bartunek and Louis (1988) may be considered an exception as they do explore the relationship of OT to OD in some detail.

Blumenthal and Haspeslagh say that a characteristic of all their cases is that 'creating behavioural change is a difficult and long-term process that requires management's concerted and persistent effort' (1994 p.101-2). Fisher and Torbert (1995) refer to transformation needing a decade or more, because of the 'lengthy and up-ending journey' (p.xv) of personal transformation that (according to the authors) individual managers necessarily undergo.

Porras and Silvers say `OT has emerged over the last decade as a distinct form of planned change. It is an advancement over OD owing to its focus on precipitating more profound change in organizations. This occurs because the variables targeted by OT approaches (organizational beliefs, purpose, and mission, the components of organizational vision) affect a "deeper" level in the organization than those traditionally targeted for change by OD (i.e., work setting variables)'. (Porras and Silvers, 1994 p.95)

As noted above, OT is associated by French et al with 'paradigm' change. But is it the case that OD has seen beliefs or purpose as being beyond its remit? Warren Bennis (1969) did not seem to think so when he wrote: 'Organization Development (OD) is a response to change, a complex educational strategy intended to change the beliefs, attitudes, values, and structure of organizations so that they can better adapt to new technologies, markets, and challenges and the dizzying rate of change itself' (Bennis, 1969 p.2).

In summary, the enterprise of Organisational Transformation is often defined in relative rather than absolute terms or on the basis of inherent characteristics. It may be contrasted with the older and (for some) less ambitious enterprise of Organisation Development, and OT is typically portrayed as being of a bigger scale relative to other forms of change. 


\section{The material and the spiritual}

Transformation is associated by some with spiritual development. This is a quite a different emphasis from the version of OT referred to by Porras and Silvers (1994), and seems to have originated in the work of Adams (1984). Harrison Owen (1995) cites 1983 as the year of the First International Symposium on Organization Transformation. Bartunek and Moch (1994) identify literature in this field from 1982 and before.

This is an emphasis more than a distinct type of practice. Owen (1990 p.viii) acknowledges that OT 'is by no means a clear-cut discipline or set of techniques. In fact it is still in the early stages of emergence.' Similarly, Dehler and Welsh argue that '...the discourse surrounding spirituality and organizational transformation remains poorly explicated in terms of both meaning and relationship with other organizational concepts'. (1994 p.18). From this emphasis, we identify four related themes; the degree of personal engagement in the transformation process; the extent to which transformation is seen as process rather than product; the extent to which transformation can be 'engineered'; and whether transformation is seen as necessarily desirable, compared with acknowledgement of its `shadow' side.

The spiritual dimension is of course difficult if not impossible to define, but recent years have seen a burgeoning interest in spirituality in organisations. In the early 1990's Pedler et al argued that 'The challenge of post-modernism and the resurgence of spiritual values, as evidenced in New Age thinking, seem to be twinned forces out of which the new era will emerge' (1991 p. 212). Since then, titles such as Hawley's 'Reawakening the Spirit in Work' (1993), Briskin's 'Stirring of the Soul in the Workplace' (1998) and Barrett's 'Liberating the Corporate Soul' (1998) have become commonplace on business bookshelves.

However, the interest in spiritual development or spiritual dimensions of experience is very evident. Bartunek and Moch (1994) emphasise the mystical nature of what they call 'third-order 
change', and the role in this of aesthetic expression. Hawkins (1991) builds on authors such as Bateson and Argyris to introduce the idea of a spiritual dimension to organisational learning. He refers to triple loop learning, 'the awareness and deeper purpose which contains and informs the strategic thinking and operational realities' (1991 p.183).

\section{Personal engagement}

Transformation of the corporation may well be a catalyst for the personal transformation of some of its members, the trigger to their own personal odyssey with both the conviction and all of the uncertainty that Ackerman suggests such spiritual transformation entails. We include here the view of Fisher and Torbert (1995) and others that the personal and the organizational domains of learning are inextricably linked. Fisher and Torbert, indeed, see personal transformation as a prerequisite for organizational transformation. We note that Fisher and Torbert do not directly advocate a spiritual perspective, but this is a characteristic of the later phases of their 'stages of personal development' model (e.g. Fisher and Torbert 1995 p. 62).

\section{Process (journey) vs. product}

The word 'transformation' has the form of a noun and so can imply that transformation is a concrete entity or product. Some usage emphasises the product dimension, such that transformation is a deliverable, or an end state. The idea of transformation as an odyssey or voyage of discovery - that may have no predictable or controllable end point - marks a significant shift from this perspective. Ackerman (1986) makes this a fundamental distinguishing feature of transformational, as opposed to what she terms developmental or transitional change. Harrison Owen expresses this by saying; 'The essence of transformation lies in the odyssey or passage of the human spirit as it moves from one formal manifestation to another' (1990 p.6). 


\section{'Leap of faith' vs. 'engineering'}

To Ackerman, the distinguishing feature of transformational change is the act of faith that precipitates it. This requires a "letting go", the process of which 'is a profound personal experience for those in position to take the risk... empowering the human spirit and changing one's beliefs about reality seem to be essential to the process. Transformation is not possible without a leap of faith, individually or organizationally' (1986 p.50). From a rational analytic perspective (a perspective that has dominated management thinking since the 1920's) such an act of faith might well appear foolish.

\section{Benign vs. 'shadow'}

Significantly, it seems to be only in this more spiritual emphasis on OT that one finds (for example, in both Harrison and Ackerman) reference to negative or pathological aspects of transformation. Virtually all of the writers we have cited elsewhere appear to consider transformation to be a "good thing", even if painful to contemplate and achieve. By contrast, Harrison (1995 p.397) comments that 'most transformations involve betrayal in the sense that they involve the unilateral transformation of explicit and implicit contracts between the organization and its members'.

For example, following the attendance of the CEO of a multinational fast-moving consumer goods business at the Chairman's Programme of a prestigious business school, the company embarked upon a programme of business process re-engineering coupled to a process in which corporate values were 'reaffirmed'. The apparent contradiction between these 'espoused' values and the company's 'values-in-use' (Argyris and Schon 1974) were such that the company's European Vice President left the organisation after having given it more than twenty years of his total commitment. In explaining his departure to one of the authors (Robinson, research in progress) he stated that the "disconnect was just too difficult to handle, it was making me ill'.

Ackerman observes that transformation `involves both birth and death. There can be profound 
pain in seeing the process through.' She also says that 'the emphasis on spirit and faith, which can help at this time, may in fact be perceived as flighty, weak or irresponsible' (1986 p.53). Personal experiences that we would label 'transformational' have been chaotic, painful and typically incidental to programmed change.

\section{The transformation matrix}

Based on the issues and dimensions reviewed above, we propose a map of contemporary usage of the term 'transformation' on a matrix (table 1). The matrix and its dimensions are our choice about how to synthesise and represent the material we have surveyed. The vertical axis represents a continuum of ends or goals of transformation, ranging from survival to fulfilment of potential. Needs to increase competitiveness or efficiency, and desires to change culture, lie within this continuum. The horizontal axis concerns the means by which the goal is pursued. 'Programme' indicates a controlled, planned method, focused on engineering transformation as a 'product'. 'Process', at the opposite end of this continuum, is essentially a commitment to, or openness to, a major change or transformation, but with no instrumental outcome or method. The notion of a 'journey' that involves a 'leap of faith', as described above, belongs here. 


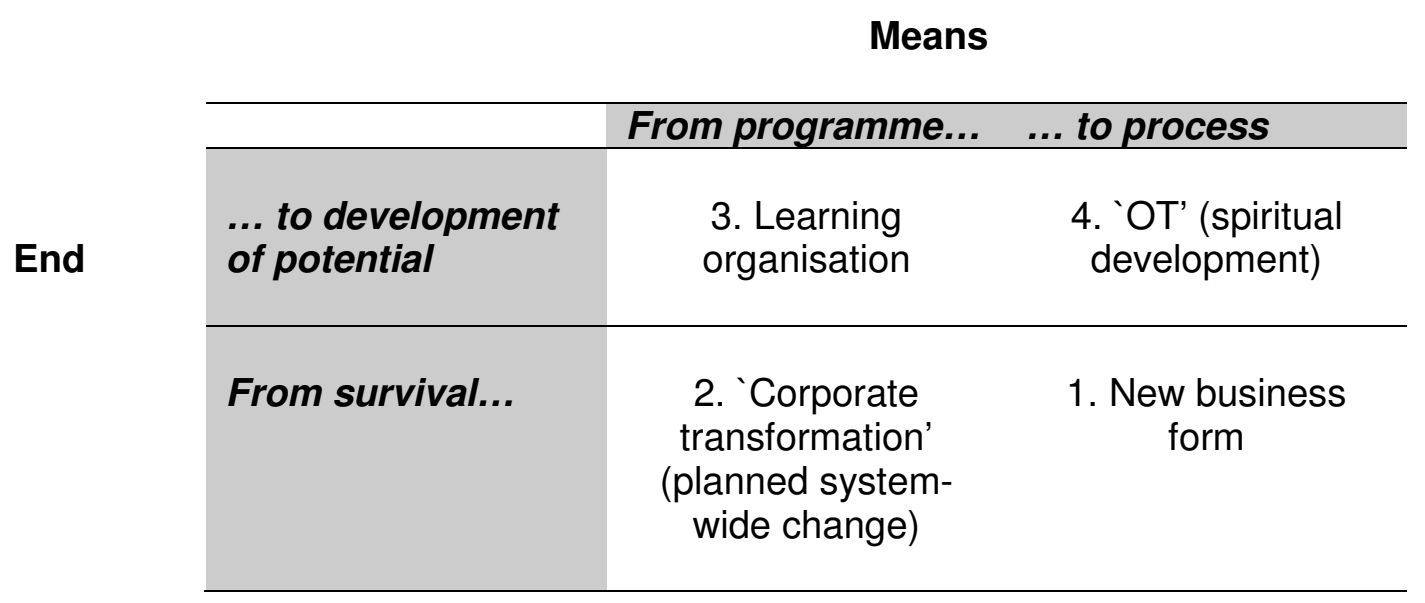

Table 1: The transformation matrix

The matrix is like many others of this kind, in that it points up contrasts. It is not suggesting that in practice, transformations necessarily fall into one of these pure types. It seems most likely that in practice there would be a mixture, with one quadrant perhaps dominant. The dimensions represent interesting tensions (e.g. between survival and development, and between product and process) played out in particular ways.

The four main varieties appearing in the quadrants of the matrix are:

\section{New business form}

So far we have concentrated on transformations that are brought about through some intentional intervention by a change agent such as an Organizational Development consultant. This quadrant represents an equally important usage of transformation, closest to the standard dictionary definition, which is the commitment to a new organizational form or entry into a new business. Such a change of form may often be an intentional choice, and it inevitably involves a discontinuity, a leap of faith (though not necessarily with any spiritual connotation). Mergers, significant changes of organizational form (e.g. from public to commercial, rather than internal restructuring) and significant changes of business belong in this quadrant. Here 'transformation' 
seems more legitimate as a literal description. This is broadly consistent with Bartunek and Louis' emphasis on transformation as 'large-scale changes in organizational form that occur throughout an organization's life cycle' (1988 p.98).

For example, in the mid nineteen-eighties the Board of U.K. company Metal Box took the unusual step of selling its core, packaging business to its French competitor, Carnaud. It then re-invented and re-branded itself as the MB Group and invested heavily in building up what had been its small subsidiary businesses in domestic heating and international security printing. The logic behind this structural 'transformation' was the Board's perception of the core business as being in terminal decline, while the former peripheral businesses were seen to have considerable growth potential.

\section{2, 'Corporate Transformation’}

In this quadrant we locate a discourse of intentional change programmes that emphasis systemwide change through a relatively controlled or planned process. Large-scale programmes such as Total Quality Management (TQM), Business Process Re-engineering, Six Sigma (Eckes 2001) and others seem characterised by a need to be more competitive or more efficient; a focus on changing behaviour; and a highly programmed, usually expert-led, method leading towards transformation as a 'product'. This seems closest to us to Blumenthal and Haspeslagh's definition of 'corporate transformation'.

\section{Learning organization}

In this quadrant, transformation involves a particular (but not exclusive) emphasis on new paradigms. Classic learning organization literature (e.g. Pedler et al 1991; Senge 1990) has a generative and evolutionary focus, particularly a view that a change of mind-set can achieve the potential of both the organization and its people. Thus the learning organization - at least in concept - seems to us to belong further along the continuum towards a concern with fulfilment of 
potential. There are also continuities from quadrant 2, for example in the strong influence of TQM. In practice, it may be that the focus on paradigm or mind-set is concerned primarily with survival, and so moves towards quadrant 2 on the matrix. Hurst (1995), for example, describes the 'resurrection' of a North American steel company that reversed a disastrous collapse of its fortunes in the wake of an over ambitious acquisition by bootstrapping itself into a new mindset through the leadership of a new and highly charismatic CEO.

\section{OT as `spiritual’ development}

Finally, the fourth quadrant is a discourse of transformation typified by a desire to fulfil potential and an emphasis on transformation as a journey that may have no specifiable goal and requires leaps of faith. We referred above to literature describing this form of OT. The themes have also emerged from empirical research (from a study one of us has conducted, consisting of semistructured, qualitative interviews with twelve OT practitioners identified on the basis of involvement in UK, European and US OT networks or as a result of being cited by other interviewees. Some were consultants, some business leaders). An inductive analysis of the transcripts yielded the following seven characteristics:

1. Practitioners refer to purposes and perspectives (global, ecological and spiritual) beyond those of the immediate organizational or business sphere.

2. Practitioners often perceive themselves as following a vocation, in the literal sense of a calling.

3. Practitioners make reference to ideals, principles, and values more than they refer to formal theory or specific methodology, to the extent that there may be a denial of using theory or technique. Links are made between this work and the notion of 'new paradigms' of thought.

4. There is often a stated intention to be integrative, in order to create synergy between (for example) the personal and the professional, and business materialism and spirituality. This sometimes has a normative status, for example that leaders should 'walk their talk' and 'live out their values'.

5. Transformation is seen as process (towards outcomes such as `alignment') more than product. 
The emphasis within accounts of the process is on concepts such as relationship, love and trust, and energy. 'Relationship' is perceived both as a context for transformation, and as an essential focus for practitioner interventions.

6. The work is predicated upon the personal transformation of both client and consultant. Leaders must go through personal transformation if they wish to create organizational transformation. Clients will need to be 'ready for' and 'committed to' this work. Consultants will need to 'invest' in the client.

7. The work may well involve intense pain and struggle for both client and practitioner, with both likely to encounter their 'shadow side'.

This quadrant appears to represent a discourse of values and beliefs. It represents a developmental intent more than a methodology for organizational change (there are, of course, methods and processes associated with how to make use of this perspective), with the implication that the potential for transformation is inherent in many types of experience.

\section{Implications and issues for practice}

\section{Working with transformation - orientation for clients and consultants}

Our analysis and matrix reflect that in practice there are various discourses of transformation. We speculate that the nature of a transformational programme, or the nature of a particular consultant or practitioner's service, is likely to differ markedly according to the quadrant on the matrix that represents their agendas, perceptual frameworks and values.

For example, a consultant with whom the authors are acquainted developed an 'executive transformation' business; this had the explicit intention of developing business leaders spiritually. The proposed method was to invite leaders to participate in retreats where, within a supportive learning community, they could and attend to their own inner development and their business role 
in an integrated way. We would place this in quadrant 4 of the matrix, diametrically opposite to transformation programmes such as Six Sigma (Eckes 2001). Whilst the term ‘transformation' is common to both, there are wide differences in purposes, beliefs and practices.

This could - given the data referred to above about OT practitioners - represent a dynamic between clients and consultants, as shown in table 2 . Here the OT consultant represents the pull towards more developmental, uncertain, personally involving dimensions of transformation, with the client representing needs for transformation to be pragmatic, controllable and close to known business needs. Of course in practice the client may well have similar aspirations to the OT consultant but, for example, not feel able whilst in their organizational role to voice them; and in many cases consultants' offerings turn out to be highly programmed. There is much potential for creativity and synergy in this dynamic; there is also potential for mismatch, misunderstanding, compromise, power struggles, and so on.

\begin{tabular}{|c|c|c|}
\hline & Means & \\
\hline & From programme... & ...to process \\
\hline $\begin{array}{l}\text {... to development } \\
\text { of potential }\end{array}$ & & Consultant \\
\hline From survival... & Client & \\
\hline
\end{tabular}

Table 2: a dynamic in transformation work

A reason to be sceptical of claims about transformation lies in the persistence of the overarching managerial discourse. All quadrants share a lack of direct questioning of managerial control and the power structures that many (for example, Clegg 1989; Coopey 1995; Dovey 1997) argue will constrain significantly the type of action and learning that are legitimised by the change process. Transformation on the developmental dimension (quadrants 3 and 4 on the matrix) may well espouse the potential for control and power issues themselves to transform or be transcended; a 
critical theory perspective is likely to see this as little more than a naïve hope. Dovey (1997) cites Clegg's view that `the language of transformation is deceptive rhetoric which masks the true intention of the capitalist elite of maintaining their hegemony in changed circumstances, through the collaborative and creative participation of workers' (Dovey, 1997 p.334).

From critical or radical perspectives, the 'mind-set' of managerial ideology is likely to remain substantially unchanged, even in 'learning organizations' in which `new paradigms' are being promulgated, if structural issues of power and control are not addressed. In the emergent literature of spirituality in organizations, it appears incontrovertible that there is scope for a rhetoric of spirituality to be subsumed within a managerial ideology, and thus to obscure rather than transform power differentials.

\section{Models of change and transformation}

Does our matrix offer anything new? In most respects it does not; it is a synthesis and specific application to the idea of transformation of existing models. The concept of transformation inevitably collapses similar qualitative differences that are enfolded within the term 'change'. We could map types of transformation onto various models of qualitatively distinct levels of change or learning proposed by authors such as Bateson (1973), Golembiewski et al (1976), Hawkins (1991) and Watzlawick et al (1974). Nutt and Backoff's analysis of organizational transformation (1997) refers to Watzlawick's notion of 'second order change', as do Bartunek and Louis (1988). Bartunek and Moch's (1994) ‘third order change’ (based on Bateson’s 'Learning III') seems broadly equivalent to our fourth quadrant, with its emphasis on mysticism and spiritual development. These are all useful maps of qualitatively different types of change.

As for further research, we hesitate to suggest that OT as such needs to be studied more. We are sceptical of the value of much of the research into OD, the learning organization, and the like, when such terms are not treated as problematic. Yet it appears that many academics, leaders and 
consultants are expressing a genuine desire to explore spiritual perspectives in relation to business contexts. We suggest that this merits research attention, both as an emergent theme of practice and as a phenomenon itself. Evidence that this is happening comes from the establishment of a new interest group titled 'Management, Spirituality and Religion' in the American Academy of Management in the year 2000.

\section{Conclusion}

In conclusion, it seems that 'transformation' is a chameleon-like term. Britain and the USA are often said to be two nations divided by a common language. A similar comment might apply to the four 'types' of Organizational Transformation mapped on the matrix. It is possible, perhaps, that our mapping of usage is redundant because the point we are making is obvious; in effect, everybody already regards ‘transformation' as a discursive device and treats it as such. Undoubtedly many people do hold this view, however the literature and practice of organizational transformation suggests that the perspective is not widespread.

We do not suggest that the term's meaning should be less elusive, or that a linguistic positivism is desirable. We have argued that it is more instructive to consider the possible purposes to which the concept is recruited, and to explore differences of usage in practice. In the literature to date, a surprising tolerance has been shown towards the diversity of guises that 'transformation' can assume. Given the prominence of the term 'organizational transformation' in consulting practice and in both practitioner and academic literature, we might expect to find greater curiosity about its usage. 


\section{References}

Ackerman, L. (1986) "Development, Transition or Transformation: The Question of Change in Organizations", in Van Eynde, D. F., Hoy, J. C. and Van Eynde, D. C. (eds.) (1997) Organization Development Classics, San Francisco: Jossey Bass

J. Adams, (ed.) (1984) Transforming Work, Virginia: Miles River Press

Argyris, C. (1987) "Double Loop Learning in Organizations", Harvard Business Review, Vol. 55 no. 5 September-October 1977 pp. 115 - 125

Argyris, C. and Schon, D. (1974) Theory in Practice: Increasing Professional Effectiveness, San Francisco: Jossey-Bass

Barrett, R. (1998) Liberating the Corporate Soul, Boston: Butterworth-Heinemann

Bartunek J.M. and Louis M. (1988) "The Interplay of OD and OT", Research In Organisational Change And Development volume 2 pp. 97-134

Bartunek J.M. and Moch K.M. (1994) "Third-Order Change And The Western Mystical Tradition”, Journal Of Organizational Change Management volume 7 no. 1 pp. 24-41

Bass, B.M. and Avolio, B.J. (eds) (1994) Improving Organizational Effectiveness Through Transformational Leadership, Thousand Oaks; Sage

Bateson, G. (1973) Steps To An Ecology Of Mind, London: Paladin, Granada

Bennis, W. (1969) Organization Development: Its nature origins and prospects, Reading, Massachusetts: Addison-Wesley

Blumenthal, B. and Haspeslagh, P. (1994) "Towards A Definition Of Corporate Transformation", in Sloan Management Review Spring 1994 pp. 101-106

Briskin, A. (1998) The Stirring of the Soul in The Workplace, San Francisco: Berrett-Koehler

Burns, J.M. (1978) Leadership, New York: Harper \& Row

Clegg, S.R. (1989) Frameworks Of Power, London: Sage

Coopey, J. (1995) "The Learning Organization, Power, Politics and Ideology", Management Learning volume 26 no. 2 pp.193-213

Dehler, G.E. and Welsh, M.A. (1994) "Spirituality and Organizational Transformation", Journal Of Managerial Psychology (Special Issue on Spirituality In Work Organizations) volume 9 no. 6 pp. $17-26$

Dovey, K. (1997) "The Learning Organization and the Organization of Learning: Power, Transformation and the Search for Form in Learning Organizations", Management Learning Vol.28 no.3 pp. 331-349

Eckes, G. (2001) The Six Sigma Revolution, New York: John Wiley 
Fisher, D. and Torbert, W.R. (1995) Personal and Organizational Transformation London: McGraw-Hill

French, W.L. and Bell, C.H. (1978) (2nd edn) Organization Development, Englewood Cliffs, New Jersey: Prentice-Hall

French, W.L., Bell C.H., and Zawacki, R.A. (eds) (1994 (4th edn) Organization Development And Transformation, Burr Ridge, Illinois: Irwin

Golembiewski, R., Billingsley, K. and Yeager, S. (1976) "Measuring Change And Persistence In Human Affairs; Types Of Change Generated By OD Designs", The Journal Of Applied Behavioural Science 1976 pp.133-157

Gordon, J. R. (1994) "The New Organizational Realities: Preparing For The 21st Century", http://www.bc.edu/bc org/avp/csom/faculty/crr/spring94/page1.html

Harrison, R. (1995) The Collected Papers of Roger Harrison, London: McGraw-Hill

Hawkins, P. (1991) "The Spiritual Dimension of the Learning Organization", Management Education and Development volume 22 part 3 pp.172-187

Hawley, J. (1993) Reawakening the Spirit in Work, San Francisco: Berrett-Koehler

Hurst, D. K. (1995) Crisis and Renewal, Boston: Harvard Business School Press

Kilmann, R., Covin, T.J. and Associates (1988) Corporate Transformation, San Francisco: Jossey Bass

Kofman, F. and Senge, P. (1993) "Communities of Commitment: the Heart of Learning Organizations”, Organizational Dynamics volume 22 part 2 pp. 5-23

Kuhn, T. (1970) (2nd edn) The Structure Of Scientific Revolutions, Chicago: University Of Chicago Press

Mezirow, J. (1991) Transformative Dimensions of Adult Learning, San Francisco: Jossey-Bass

Nutt, P.C., and Backoff, R.W. (1997) "Organizational Transformation", Journal of Management Inquiry volume 6 no. 3 pp 235 - 254

Owen, H. (1990) Spirit: Transformation and Development in Organizations, Potomac, Maryland: Abbott Publishing

Owen, H. (ed) (1995) Tales From Open Space, Maryland: Abbott Publishing

Pedler, M. (1994) "Organizational Biography and Organizational Learning: Weldrick: a Case Study and Commentary", in J. Burgoyne, M. Pedler and T. Boydell (eds) (1994) Towards The Learning Company London: McGraw-Hill

Pedler, M., Boydell, T. and Burgoyne, J. (1989) "Towards the Learning Company", Management Education and Development volume 20 part 1 pp 1-8

Pedler, M., Burgoyne, J. and Boydell, T. (1991) The Learning Company, London: McGraw-Hill

Porras, J.I. and Silvers, R.C. (1994) “Organization Development and Transformation”, in French, 
W.L., Bell C.H., and Zawacki, R.A. (eds) (1994 (4th edn) Organization Development And Transformation Burr Ridge, Illinois: Irwin

Robinson, G. and Hurley, C. (1996) "Management Development And Transformation In The Guernsey Public Sector", Industrial And Commercial Training volume 28 no. 3 pp. 19-25

Senge, P. (1990) The Fifth Discipline, London: Century Business, Random Century

Torbert, W. (1991) The Power Of Balance, Newbury Park, California: Sage

Watzlawick, P., Weakland, J. and Fisch, R. (1974) Change - Principles of Problem Formation and Problem Resolution, New York: W.W. Norton 